\title{
Digitalization of Economic Evaluation of Mineral Deposits
}

\author{
Juraj Janocko ${ }^{1, *}$, Marina Ryzhkova ${ }^{2,3}$, Tatiana Mamzina ${ }^{4}$, and Sergey Bereznev ${ }^{4}$ \\ ${ }^{1}$ Technical University of Kosice, Faculty of Mining, Ecology, Process Control and Geotechnologies, \\ Letná 9, 04200, Kosice, Slovak republic \\ ${ }^{2}$ National Research Tomsk State University, 63405036 Lenin ave., Tomsk, Russia \\ ${ }^{3}$ National Research Tomsk Polytechnic University, 63405030 Lenin ave., Tomsk, Russia \\ ${ }^{4}$ T.F. Gorbachev Kuzbass State Technical University, 650000, 28 Vesennyaya Street, Kemerovo, \\ Russia
}

\begin{abstract}
The issue of mineral deposit evaluation is very topical and the aim of the present article is to fill a gap, which with far has been empty. The presented results of research are aimed to describe these issues in a comprehensive way. After the changes to the economic systems in many European countries the criteria of assessment and evaluation of mineral deposits have changed significantly, and authors of these "recomputations and calculations" use various methods. In these methods the main provisions are built upon geological and industrial values, specifications and indicators, so the economic trends are not completely considered. Therefore, in coming post-industrial era the structure of mineral resources use has been changed, and the leading methods of mineral deposits evaluation must include sufficient economic values, with a new codification.
\end{abstract}

\section{Introduction}

With regard to the various understanding of notions - sources of mineral raw materials, deposits and mineral raw material reserves, mines, quarries, etc., it is worth defining the basic notions used in the deposit geology, mining and economy of mineral raw materials, i.e. in specializations that support the evaluation of mineral raw material resources.

Earth resources are abiotic resources from the lithosphere, hydrosphere and atmosphere that can be excavated or obtained by means of existing and available technologies with the aim of meeting the needs of human beings. Earth resources are also a reflection of the human approach as well as the development of civilization and technologies. The development of inventions, technologies, trade, business, market requirements, investments, social and political events and institutions that control world trade as well as social relations within or between states may form a world-wide need that creates a required earth resource e.g. from a raw material that either has not been used so far at all or has been used only locally [1-2].

\footnotetext{
*Corresponding author: juraj.janocko@tuke.sk
} 
A Mineral raw material (primary mineral raw material) is a mineral natural substance, which was, is or will be (under defined conditions) used in production or consumption processes due to the content of its industrial components.

A Source of mineral raw material is, at present (or under precisely defined conditions), an extractable part of a retrieved or explored deposit as well as a deposit reasonably anticipated on the basis of geological conditions. Sources of mineral raw materials also include the earth's atmosphere, seas, oceans and mineral water springs.

Other mineral raw materials belong to non-metallic raw materials or fossil kaustobiolites.

A Deposit of mineral raw materials is such an association of mineral bodies in the earth's crust, which, based on its position, quality and quantity of mineral raw materials, meets the condition of immediate industrial exploitability both from the technical and economic viewpoint. The term "deposit of mineral raw materials" is also used for each natural occurrence, which was exploited for production purposes in the past.

Occurrence (prospect) of mineral raw materials is a mineral raw material resource which has not been exploited so far, and the reserves of which could be verified by its further exploration. Thus the occurrence can become a deposit. This assumption is based on the physical presence of mineral raw materials verified by geological prospecting (in boreholes or exposures).

Reserves of mineral raw materials are parts of currently mineable mineral raw material resources, the quantity and quality of which has been calculated in their original state, "in the earth".

Calculation of mineral deposit reserves - it is a calculation (estimation) of the quantity and quality of reserves in a deposit or the estimation of quantity and quality of resources (prognosis resources) serving for the evaluation of mineral raw material deposits [3-4].

\section{Materials and Methods}

When calculating reserves it is necessary to distinguish between [5-6]:

- geological reserves $Q_{g}$, which are the result of alternative calculations of reserves, and make a basis for the calculation (estimate) of extractable reserves. Out of geological reserves, only free reserves are considered for the purpose of technical and economic assessment, while blocked reserves are excluded from this process. The division of geological reserves to balancing (economic) a non-balancing (sub-economic) only results subsequently from alternative calculations of deposit reserves. The division of geological reserves into balancing a non-balancing in accordance with the conditions of the feasibility of reserves set in advance cannot be considered suitable;

- extractable reserves $Q_{v}$, which consider recovery $v$ and contamination $z$ and are calculated by means of the following formula:

$$
\mathrm{Q}_{\mathrm{v}}=\frac{\mathrm{Q}_{\mathrm{z}} \cdot \mathrm{v}}{100-\mathrm{z}}
$$

The basis of the price of an industrial mineral is its utility value. However, it is not related to the costs spent to gain it. A raw material price is given by natural properties. The difference between the raw material price and a production price is called the differential mining rent - DMR, i.e.:

$$
\text { DMR }=\text { Production Costs }+ \text { Planned Profit }
$$

While this difference caused by natural conditions is a DMR of type „I“, and the one caused by technical equipment of mines and a following processing plant, which is a part of the mining company, is a DMR marked as DMR „II“. After the change in economic rules 
geologists and economists used to consider the differential mining rent the mining industry an indicator evaluating the deposit price for which the deposits of industrial minerals should be rented to private companies. The differential mining rent should be transferred to the government as unearned profit of a mining company conducting business on a deposit. Then a marginal deposit, i.e. a deposit from which only a planned profit is gained, has a zero value and the price of other deposits is equal to the differential mining rent.

However, the differential mining rent is neither a suitable nor useful tool for such a comprehensive issue such as the evaluation of deposits. The most frequently used methods evaluate deposits by means of a business project implemented on a deposit. Mathematic methods used in mineral deposits evaluation sometimes are rather complicated, as well as in the whole mining science, and may involve application of differential equations [7].

The following is an example that documents how an earth resource can be evaluated by a project. Nobody doubts the existence of solar energy. It is difficult to evaluate this source differently than by means of a project focusing on the use of this energy. The resource considered in this project is quantified by solar energy intensity and time of radiation, technologies used, for example, for the production of hot non-drinking water, distribution of energy, its use by end users, etc. The project also involves non quantifiable indicators such as the environmental "sense" of customers, the effort to use "clean" and renewable energy resources, etc. Based on the project it determines whether the resource will or will not be used. This is a very simplified and suitable example of how to proceed with the evaluation of any earth resource. Thus the price of one and the same deposit of mineral raw materials may vary depending on the various factors accompanying the extraction, processing and sale of the raw material [10].

In accordance with their suitability for industrial purposes the reserves can be classified as [8-9]:

a) balancing reserves;

b) non-balancing reserves.

Balancing reserves are reserves usable at present, which meet the current technical, technological and economic conditions for the use of a state owned deposit or its part.

Non-balancing reserves are reserves unusable at present, however in the future their efficiency can be assumed with regard to expected technical, technological and economic development.

In accordance with the possibilities of extraction conditioned by extracting technologies, safety of operation and defined protective pillars, the reserves are classified as:

a) blocked reserves;

b) free reserves.

The Principles of Evaluation of Reconnaissance Mineral Resources include the following: 1. Reconnaissance mineral resources are estimated to the depths accessible to the current or future mining in accordance with current economic, mining, technical, technological and other conditions, while considering possible changes of these conditions in the future. The estimation is carried out in units of mass or tonnage in a limited reconnaissance area.

2. The quantity of reconnaissance mineral resources is defined on the basis of expert estimations within the limits of large regions, basins or parts of deposit units.

3. Reconnaissance mineral resources are divided into:

a) reconnaissance mineral resources $P 1$, the presence of which, based on the positive evaluation of deposit indications and anomalies detected during geological mapping and geophysical, geochemical and other work, is assumed in basins, mining properties or geological regions, where deposits of identical formation and genetic type are known. The estimation of reconnaissance mineral resources in assumed deposits and the idea of the shape 
and size of deposit bodies, their composition and quality are based on the analogy with these known mineral deposits;

b) reconnaissance mineral resources $\mathrm{P} 2$, the presence of which, based on favourable stratigraphic, litologic, tectonic and paleographic assumptions identified in the evaluated area during geological mapping and by the analysis of geophysical and geochemical data, is assumed in the evaluated area. The estimation of quantity and quality of reconnaissance mineral resources is based on analogy with other areas examined in more detail, in which deposits of the identical genetic and formation type have been found and verified.

\section{Results and Discussion}

The terms "reserves" and "resources" have many meanings in various national classification systems throughout the world, and many of them have a long history. Being used for international classification within the $\mathrm{UN}$ framework classification system, they are partially redefined. This can happen, for example, if the term is supported by a corresponding country.

Both terms and definitions submitted by many countries in a questionnaire have been discussed in detail during a workshop in Hanover. The resulting questionnaires prove that many countries use either the former or latter term; however, in some countries resources are not a part of reserves, but their addition.

The proposal stated below was developed during the workshop in Leoben in May 1996. Total mineral resources are defined as a naturally occurring concentration of mineral raw materials of economic interest and with specified geological assurance. Mineral reserves represent the economically mineable part of total mineral resources according to their feasibility assessment definition. Remaining mineral resources represent the balance of the total mineral resources that have not been identified as reserves. Remaining mineral resources are divided into 8 classes, illustrated in Figure 1 and defined in the Definitions the terms of mineral reserves/resources in the $\mathrm{UN}$ framework classification system.

\begin{tabular}{|c|c|c|c|c|c|}
\hline $\begin{array}{l}\text { Classification } \\
\text { System }\end{array}$ & UN & $\begin{array}{l}\text { Detailed } \\
\text { exploration }\end{array}$ & $\begin{array}{l}\text { General } \\
\text { exploration }\end{array}$ & Prospecting & $\begin{array}{c}\text { Reconnaissance } \\
\text { exploration }\end{array}$ \\
\hline & $\begin{array}{l}\text { National } \\
\text { system }\end{array}$ & 1 & 2 & 3 & 4 \\
\hline $\begin{array}{l}\text { Detailed } \\
\text { feasibility } \\
\text { study and/or } \\
\text { mining report }\end{array}$ & & $\begin{array}{l}\text { 1. proved } \\
\text { reserves } \\
\text { (111) } \\
\text { 2. } \\
\text { prefeasibility } \\
\text { resources } \\
(221)\end{array}$ & & \multirow{2}{*}{\multicolumn{2}{|c|}{$\begin{array}{l}\text { usually } \\
\text { irrelevant }\end{array}$}} \\
\hline $\begin{array}{l}\text { Pre- } \\
\text { feasibility } \\
\text { study }\end{array}$ & & $\begin{array}{l}\text { 1. probable } \\
\text { reserves } \\
\text { (121) } \\
\text { 2. } \\
\text { prefeasibility } \\
\text { sources } \\
(221)\end{array}$ & $\begin{array}{l}\text { probable } \\
\text { reserves } \\
(122) \\
\text { prefeasibility } \\
\text { resources } \\
(222)\end{array}$ & & \\
\hline $\begin{array}{l}\text { Initial } \\
\text { feasibility } \\
\text { study }\end{array}$ & & $\begin{array}{l}1-2 . \\
\text { measured } \\
\text { resources } \\
(331)\end{array}$ & $\begin{array}{l}1-2 . \\
\text { indicated } \\
\text { resources } \\
(332)\end{array}$ & $\begin{array}{l}1-2 . \\
\text { inferred } \\
\text { resources } \\
(333)\end{array}$ & $\begin{array}{l}\text { ? } \\
\text { Reconnaissance } \\
\text { resources (334) }\end{array}$ \\
\hline
\end{tabular}

Fig. 1. Terminology of reserves and resources proposed by the UN.

Along with the classification of reserves/resources there are also the so called mineralogical occurrences, which are not a part of the reserves/resources and represent 
mineralization without specific geological assurance, or non-economic occurrences - mineral concentrations lacking economic importance. Detailed definitions of these terms are stated in Appendix II. Both terms have been defined to demonstrate limits within the UN framework classification system and simultaneously to clarify various meanings conveyed by these terms at present.

\section{The Codification}

The inclusion of existing classifications into the UN framework classification system and their comparison is not simple due to the fact that codification is considered an interface. The codification has other advantages in providing short, unambiguous identification of the reserve/resource classes which facilitates computer processing of data and exchange of information. During a workshop in Hanover the Codification system was developed in detail. At the end of this meeting the numerical codification of the UN framework classification was approved as the most suitable system.

A geological study involves a preliminary evaluation of the economic viability, which is the first stage on the axis when evaluating possibilities.

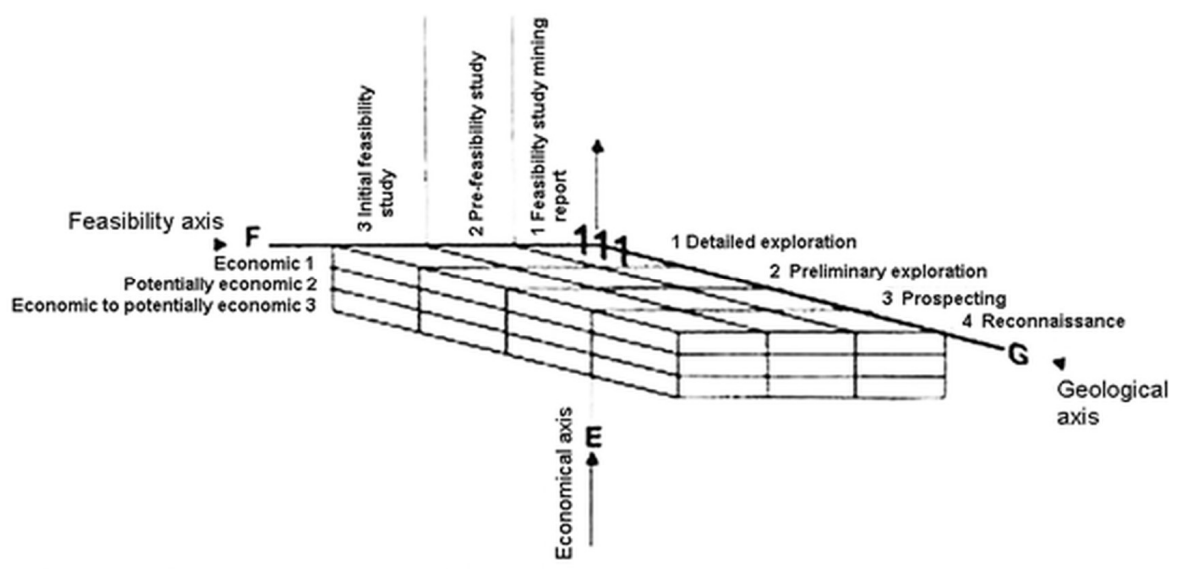

Fig. 2. Principles of the UN framework classification of reserves and resources in 3D perspective.

Fig. 2 displays the proposed principles of the UN classification system, while the $3 \mathrm{D}$ categorization is represented by axes: $\mathrm{E}$ (economic) for economic efficiency, $\mathrm{F}$ (feasibility) for stages of the feasibility assessment and G (geological) for stages of the geological study. The digits are quoted in the order EFG firstly because alphabetical order is easier to remember and secondly, the first digit refers to economic viability, which is the decisive meaning for mining organisations and investors.

Numbers are used to designate the different classes. The lowest number, in accordance with the rule that "one" is the best, reflects the highest degree of economic viability on the $\mathrm{E}$ axis, and the highest degrees of assurance on the $\mathrm{F}$ and $\mathrm{G}$ axes.

Figure 3 represents disintegrated three dimensional layers of Figure 1 displaying the codified classes which are applicable in practice.

The class coded 111 shown in Fig. 2 and 3 is the most relevant for an investor as it represents quantities that are economically mineable (number 1 as the first digit), have been 
proved by a detailed feasibility study or actual mining (number 1 as the second digit), and are based on detailed geological exploration (number 1 as the third digit).

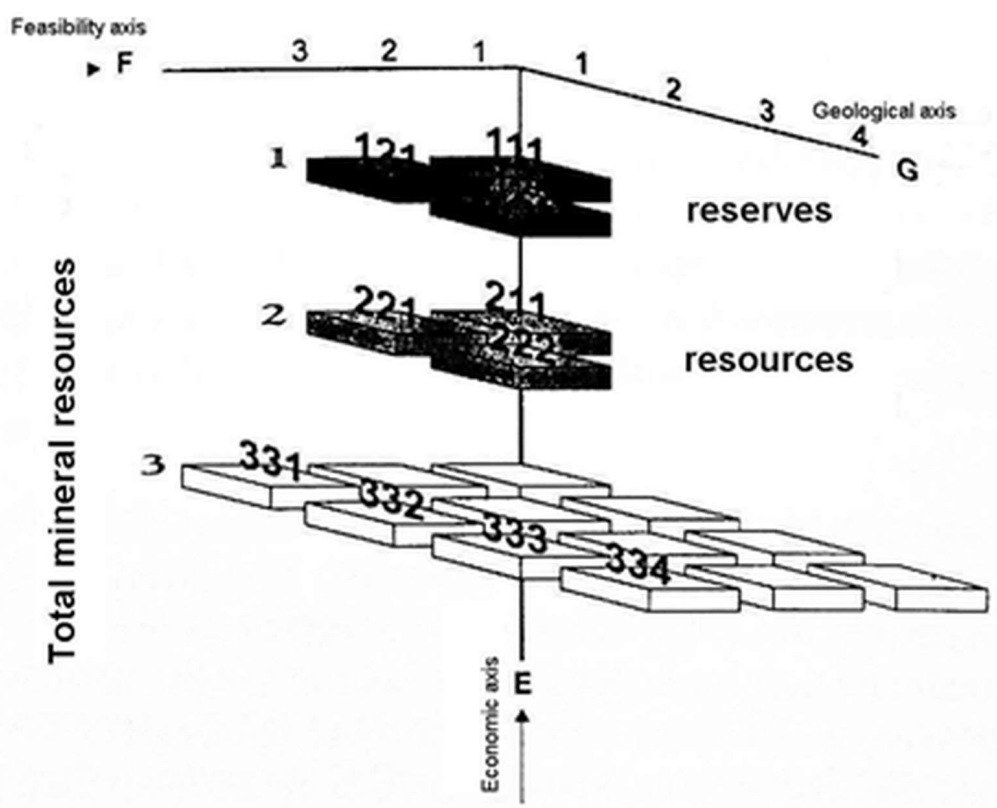

Fig. 3. Codified categories of the UN classification of reserves and resources applicable in practice.

Each codified class defines a specific assessment of economic viability stages, which are shown in Table 1. According to this table all types of reserves and resources can be codified, and each class can be transferred from one system into another.

Table 1. Classification of classes.

\begin{tabular}{|c|c|c|c|}
\hline Economic axis & Feasibility axis & Geological axis & Code \\
\hline economic & $\begin{array}{c}\text { detailed feasibility study and } \\
\text { mining report }\end{array}$ & detailed exploration & 111 \\
\hline economic & pre-feasibility study & detailed exploration & 121 \\
\hline pconomic & pre-feasibility study & general exploration & 122 \\
\hline potentially economic & $\begin{array}{c}\text { detailed feasibility study and } \\
\text { mining report }\end{array}$ & detailed exploration & 211 \\
\hline potentially economic & pre-feasibility study & detailed exploration & 221 \\
\hline potentially economic & pre-feasibility study & general exploration & 222 \\
\hline $\begin{array}{c}\text { economic to potentially } \\
\text { economic }\end{array}$ & initial feasibility study & detailed exploration & 331 \\
\hline $\begin{array}{c}\text { economic to potentially } \\
\text { economic }\end{array}$ & initial feasibility study & general exploration & 332 \\
\hline $\begin{array}{c}\text { economic to potentially } \\
\text { economic }\end{array}$ & initial feasibility study & prospecting & 333 \\
\hline $\begin{array}{c}\text { economically not defined } \\
\text { initial feasibility study }\end{array}$ & reconnaissance \\
exploration & 334 \\
\hline
\end{tabular}




\section{Conclusion}

The evaluation of the economic effectiveness of the mining business belongs in the recent economic environment between basic activities which should necessarily be done to obtain a contribution from a project from the point of view of an optimum utilisation of the Earth, human and financial resources and a contribution or minimum impact from the point of view of environmental protection. The economic evaluation of projects focuses on the financial environment in which the aim is to invest in a project in such a way so as to gain value at its termination which refund paid in investments and at the same time to bring financial means which can be used for the further development of the firm e.g. investing into new technologies or to increase the company's assets.

\section{References}

1. V.L. Martyanov, Journal of Mining and Geotechnical Engineering, 1, 35-41 (2018) DOI: 10.26730/2618-7434-2018-1-35-41

2. V.A. Ermolaev, A.V. Selyukov, Journal of Mining and Geotechnical Engineering, 2, 5064 (2018) DOI: 10.26730/2618-7434-2018-2-50-64

3. Th.F. Torries, Evaluating Mineral Projects: Applications and Misconceptions (Society for Mining, Metallurgy and Exploration, Littleton, 1997)

4. H. Wackernagel, Multivaiate geostatistics (Springer Verlag. Berlin, 1995)

5. H.A. Fraser, D.S. Richard, Economics of Worldwide Petroleum Production (Oil \& Gas Consultants International, Inc., Oklahoma, 1993)

6. T.A. O’Hara, S.C. Suboleski, Cost and Cost Estimation. SME Mining Engineering Handbook (Springer Verlag. Berlin, 1992)

7. D.Yu. Sirota, M.A. Babushkin, Journal of Mining and Geotechnical Engineering, 2, 65-74 (2018) DOI: 10.26730/2618-7434-2018-2-65-74

8. M. Armstrong, P.A. Dowd, Geostatistical simulations (Kluwer academic publishers, London, 1994)

9. B. Cavender, Determination of the optimum lifetime of a mining project using discounted cash-flow and option pricing techniques (Mining Engineering, New York, 1992)

10. A.V. Katsubin, E.V. Makridin, Journal of Mining and Geotechnical Engineering, 1, 8188 (2018) DOI: 10.26730/2618-7434-2018-1-81-88 